\title{
PERANCANGAN APLIKASI PENGENALAN CERITA DAN DOA NABI BERBASIS ANDROID
}

\author{
Febri Budi Utomo ${ }^{1}$, Forkas Tiroy Santos Butar-Butar ${ }^{2}$, Ai Solihah ${ }^{3}$ \\ Program Studi Teknik Informatika, Fakultas Teknik dan Ilmu Komputer, \\ Universitas Indraprasta PGRI \\ Jalan Raya Tengah No 80, Kelurahan Gedong, Pasar Rebo, Jakarta Timur \\ febri.354@ gmail.com ${ }^{1}$, fortysant.bb@gmail.com ${ }^{2}$, faztasy@yahoo.com ${ }^{3}$
}

\begin{abstract}
Abstrak
Teknologi semakin cepat berkembang dan salah satunya adalah teknologi smartphone. Dalam hal ini sebuah smartphone pastinya membutuhkan suatu aplikasi dan informasi kepada para pengguna terutama beberapa masyarakat pastinya belum tahu banyak tentang Cerita Nabi dan Doa Nabi . Jadi tujuan dari penelitian adalah untuk membantu anak-anak dan masyarakat khususnya yang beragama Islam dalam mengenai. Cerita Nabi dan Doa Nabi dengan sebuah smartphone berbasis Android. Dengan adanya aplikasi ini pengguna bias lebih mudah beredukasi dalam mengetahui sejarah-sejarah setiap Nabi dan doa Nabi terutama untuk anak-anak, karena bias diakses langsung melalui sebuah smartphone tanpa harus mencari terlebih dahulu melalui internet. Dan peneliti membuat aplikasi ini bagaimana agar anak-anak tertarik dengan aplikasi ini, dalam aplikasi ini terdapat teks cerita. Nabi dan video animasi yang menjelaskan dari teks cerita tersebut. Dan terdapat doa Nabi dalam bentuk audio dan kuis agar mempermudah pengguna mengetahui cerita dan doa Nabi. Dalam perancangan aplikasi ini, metode yang digunakan oleh peneliti adalah metode Grounded Research yaitu metode penelitian berdasarkan fakta, pengumpulan data, studi Pustaka dan observasi. Dengan metode pengembangan sistem yang digunakan adalah Modified Waterfall. Setelah peneliti membuat perancangan aplikasi pengenalan cerita Nabi dan doa Nabi berbasis android, peneliti dapat menarik kesimpulan bahwa program ini dapat mempermudah pengguna terutama bagi anak-anak dalam beredukasi.
\end{abstract}

Kata Kunci: Perancangan Aplikasi, Cerita 25 Nabi, Doa Nabi, Kuis, Android

\begin{abstract}
Technology is growing faster and one of them is smartphone technology. In this case, a smartphone certainly requires an application and information to users, especially some people, of course, don't know much about the Prophet's Story and the Prophet's Prayer. So the purpose of the research is to help children and the community, especially those who are Muslim, in understanding. Stories of the Prophet and Prayers of the Prophet with an Android-based smartphone. With this application, users can be easier to educate in knowing the histories of each Prophet and the Prophet's prayers, especially for children, because it can be accessed directly through a smartphone without having to search through the internet first. And researchers made this application how to get children interested in this application, in this application there is a story text. Prophets and animated videos explaining the text of the story. And there are prayers of the Prophet in the form of audio and quizzes to make it easier for users to know the stories and prayers of the Prophet. In designing this application, the method used by the researcher is the Grounded Research method, namely research methods based on facts, data collection, library studies and observations. The system development method used is Modified Waterfall. After the researchers designed an android-based application for the introduction of the Prophet's story and the Prophet's prayer, the researcher could draw the conclusion that this program can make it easier for users, especially for children to educate.
\end{abstract}

Keywords: Application Design, Story 25 of Prophets, Prayer of Prophets, Quiz, Android

\section{PENDAHULUAN}

Pertumbuhan teknologi semakin cepat secara menyeluruh diberbagai bidang dan salah satunya adalah smartphone. Teknologi smartphone ini tentunya didukung oleh sistem operasi yang terus dikembangkan supaya fitur-fitur yang terdapat di smartphone terus bertambah seperti berbagi informasi. Teknologi informasi adalah suau teknologi yang berhubungan dengan pengolahan data menjadi informasi dan proses penyaluran data informasi tersebut dalam batas-batas ruang dan waktu (Indrajit 2011). Smartphone juga dapat dimanfaatkan untuk sarana dakwah Islam, 
diantaranya pendukung media edukasi terutama bagi kalangan anak-anak dalam pengenalan cerita 25 Nabi dan beserta doa Nabi yang sesuai dalam Al-Qur'an. Teknologi beberapa di kalangan masyarakat ada yang belum mengetahui tentang cerita 25 Nabi dan doa Nabi, terutama untuk anak usia dini yang semestinya mulai sudah mengetahuinya. Dalam hal ini kurangnya minat membaca buku referensi sejarah dan kurang cepat tanggap dan masih banyak orang yang belum mengetahui nama-nama Nabi, sejarah Nabi maupun doa Nabi. Sebagian masyarakat juga sulit dalam mencari tentang cerita Nabi dan doa Nabi melalui internet, karena terlalu banyak referensinya dan kurang begitu praktis dikarenakan harus membutuhkan sambungan data dan itu menguras kouta internet pengguna. Dengan menggunakan aplikasi ini pengguna hanya perlu tinggal membukanya dan tidak usah mencari di internet lagi. Berdasarkan uraian tersebut, peneliti akan membuat judul "Perancangan Aplikasi Pengenalan Cerita Dan Doa Nabi Berbasis Android" yang dapat membantu pengguna mengetahui sejarah cerita Nabi dan doa Nabi. Peneliti juga memberikan pertanyaan dalam kuis, bertujuan agar memberikan nilai-nilai teladan yang terkandung dalam Cerita Nabi dan Doa Nabi. Perancangan adalah sebuah proses untuk mendefinisikan sesuatu yang akan dikerjakan dengan menggunakan teknik yang bervariasi serta didalam nya melibatkan deskripsi mengenai arsitektur serta detail mengenai komponen dan juga keteratasan yang akan di alami dalam proses pengerjaannya (Rizky 2011). Perancangan merupakan penggambaran, perencanaan, pembuatan seketsa dari beberapa elemen yang terpisah kedalam satu kesatuan yang utuh dan berfungsi (Hidayat 2016). Kusmanto juga menambahkan bahwa aplikasi adalah software yang dirancang khusus untuk membantu pengerjaan tugas-tugas yang diperlukan dan program yang siap pakai untuk digunakan (Kusmanto 2018). Menurut Nazruddin, Android merupakan sistem operasi untuk telepon selurer yang berbasis Linux. Android menyediakan platform terbuka bagi para pengembangnya untuk menciptakan aplikasi mereka sendiri untuk digunakan oleh bermacam peranti bergerak. Android umumnya digunakan di smartphone dan juga tablet pc (Nazruddin Safaat H 2012).

\section{PENELITIAN RELEVAN}

Penelitian pertama (Gun Gunawan and Bunyamin 2016) membahas mengenai untuk membangun suatu aplikasi yang berbasis Android yang dapat menyampaikan kisah Nabi dan Rasul menjadi lebih interaktif. Dengan metode yang digunakan adalah metode pengembangan sistem multimedia Luther-Sutopo dan untuk pengujuan aplikasi menggunakan metode pengujian metode Black Box dan pengujian Beta terhadap kepuasan pengguna. Hasil dari penelitian ini berupa aplikasi kisah 25 Nabi dan Rasul yang berisi materi tentang kisah 25 Nabi dan Rasul yang terdapat di fitur evaluasi berupa pertanyaan-pertanyaan yang berupa kuis sehingga lebih interaktif serta menambahkan, dalil-dalil Al-Qur'an yang dapat memperkuat kisah 25 Nabi dan Rasul.

Penelitian kedua (Afriansyah 2018) membahas mengenai membuat aplikasi doa harian yang dapat memberikan kemudahan bagi pengguna dalam mempelajari doa yang berbasis mobile. Aplikasi do'a harian umat muslim berbasis android merupakan sebuah aplikasi yang diterapkan pada smartphone android yang mana akan sangat berguna bagi pengguna smartphone sehingga mempermudah mereka membaca doa-doa harian tanpa harus bingung mencari atau membeli buku dengan mengeluarkan biaya dan waktu. Aplikasi ini terdiri dari menu doa harian yang berisikan 30 doa sehari-hari yang dilengkapi dengan tulisan Bahasa Arab, tulisan latin, terjemahan ke Bahasa Indonesia serta dilengkapi dengan adanya fitur suara yang akan mempermudah user dalam mengetahui cara pembacaan doa tersebut. Aplikasi ini menggunakan metode RAD yang menekankan pada sebuah keterurutan dalam proses pengembangan perangkat lunak untuk waktu pengerjaan yang pendek.

\section{METODE PENELITIAN}

Metode penelitian merupakan cara ilmiah untuk mendapatkan data dengan tujuan dan kegunaan tertentu (Sugiyono 2013). Jadi metode penelitain itu untuk mendapatkan data yang dicari untuk mencapai tujuan tertentu. Desain penelitan yang digunakan oleh peneliti adalah desain penelitan kualitatif, penelitan kualitatif yaitu penelitan tentang riset yang bersifat dekritif dan cenderung menggunakan analisis. Metode kualitatif ini digunakan karena beberapa pertimbangan, pertama, menyesuaikan metode kualitatif lebih mudah apabila berhadapan dengan kenyataan yang ada. 
Kedua, metode ini lebih peka dan lebih dapat diri dengan menyesuaikan banyak penajaman pengaruh bersama terhadap pola-pola nilai yang dihadapi. Metode penelitian yang digunakan oleh peneliti dalam tugas akhir ini adalah metode grounded (grounded research) yaitu suatu metode penelitian berdasarkan fakta, dengan tujuan mengadakan generalisasi empiris, menetapkan konsep, membuktikan teori, mengembangkan teori, pengumpulan dan analisis data dalam waktu yang bersamaan. Setelah mengumpulkan data, peneliti melanjutkan proses penelitian sesuai dengan langkah-langkah pokok yang ingin diselidiki, mengumpulkan data atau informasi yang ada, menganalisis dan menjelaskan masalah yang ditemukan serta membuat laporan hasil penelitian. Dan untuk pengembangan sistemnya menggunakan Metode Modified Waterfall. Model waterfall adalah model klasik bersifat sistematis, berurutan dalam membangun software (Pressman, Roger S. 2014). Dalam pengembangan sistem aplikasi ini, peneliti mengumpulkan data, tahapan perencanaan, tahapan perancangan dan permodelan arsitektur sistem dan tahapan proses penerjemahaan bentuk desain menjadi kode yang dibaca oleh mesin.

Teknik pengumpulan data yang digunakan oleh peneliti dalam melakukan pengumpulan data :

1. Studi Kepustakaan

Studi ini dilakukan dengan mempelajari buku-buku perpustakaan, jurnal, skripsi dan mencari informasi melalui internet. Serta peneliti mengambil kesimpulan dari data dan infomarsi melalui pustaka yang erat kaitannya.dengan permasalahan yang dibahas. Metode ini juga dijadikan referensi dalam penelitian dan juga dari bahan-bahan tersebut di ambil teori-teori untuk menganalisa dalam penelitian ini.

2. Observasi

Observasi merupakan pengamatan dan pencatatan seistematik terhadap unsur-unsur yang tampak dalam suatu gejala atau gejala-gejala dalam objek penelitian. Peneliti melakukan observasi berupa pengamatan terhadap anak-anak dan orang tua.

\section{HASIL DAN PEMBAHASAN}

Aplikasi cerita dan doa Nabi berbasis Android ini dibangun menggunakan bahasa pemograman JAVA, Android Studio 4.0 sebagai editor Android. Aplikasi ini memuat 25 Nabi beserta 20 doa Nabi yang dilengkapi dengan video animasi dan audio untuk doanya. Terdapat kuis agar mempermudah pengguna dalam mengetahui cerita 25 Nabi dan doa Nabi. Dalam merancang sebuah gambaran pembuatan suatu sistem peneliti menggunakan Unifield Modeling Language (UML), Bahasa visual untuk pemodelan dan komunikasi megenai sebuah sistem dengan menggunakan diagram dan teks-teks pendukung (A. S., Rosa dan Shalahuddin 2013).

\section{Use Case Diagram}

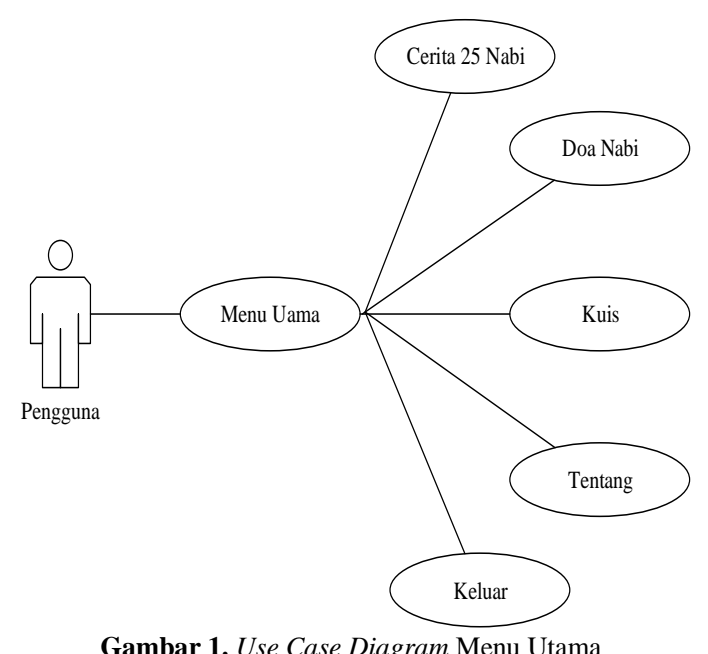




\section{Class Diagram}

Activity Diagram

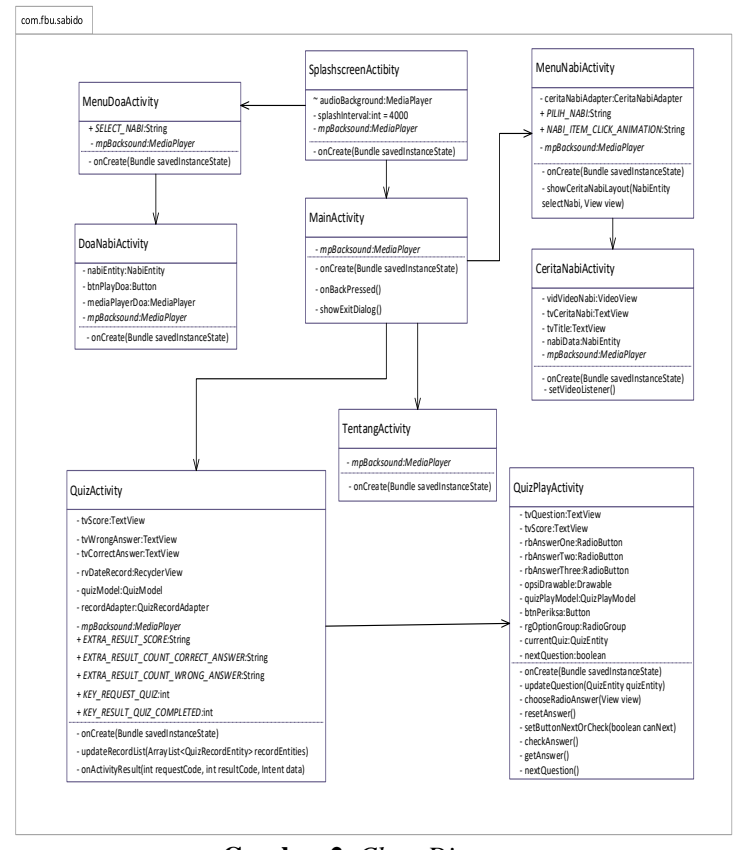

Gambar 2. Class Diagram

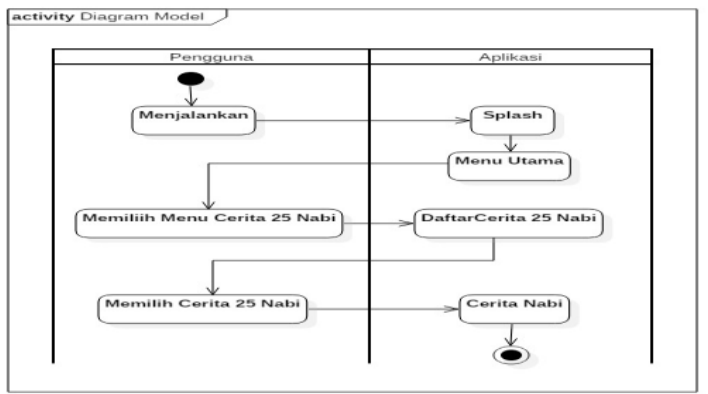

Gambar 3. Activity Diagram Cerita 25 Nabi

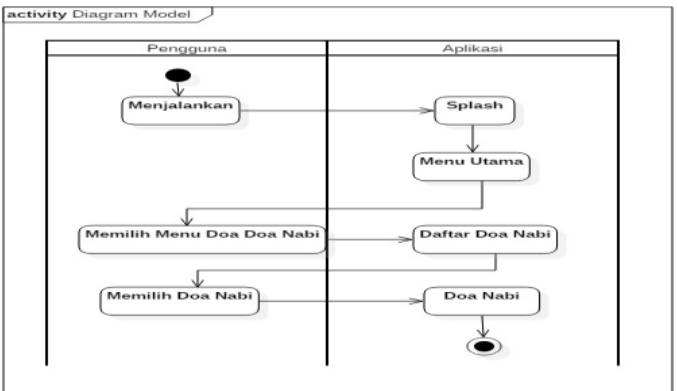

Gambar 4. Activity Diagram Doa Nabi

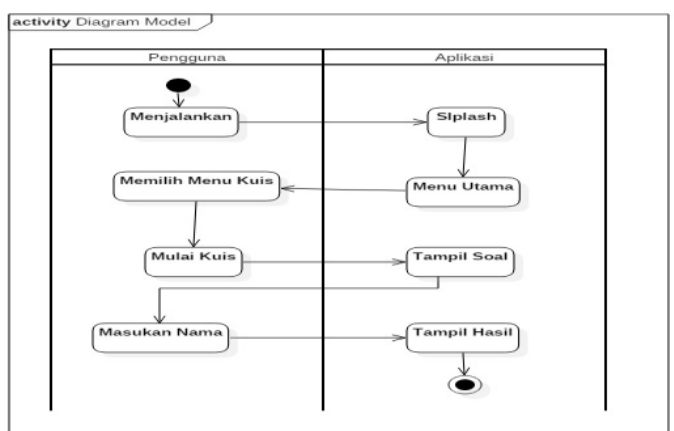

Gambar 5. Activity Diagram Kuis 
Jurnal Riset dan Aplikasi Mahasiswa Informatika (JRAMI)

Vol Q2 No Q3 Tahun ZOZI

e-ISSN : $2715-8756$

\section{Sequence Diagram}

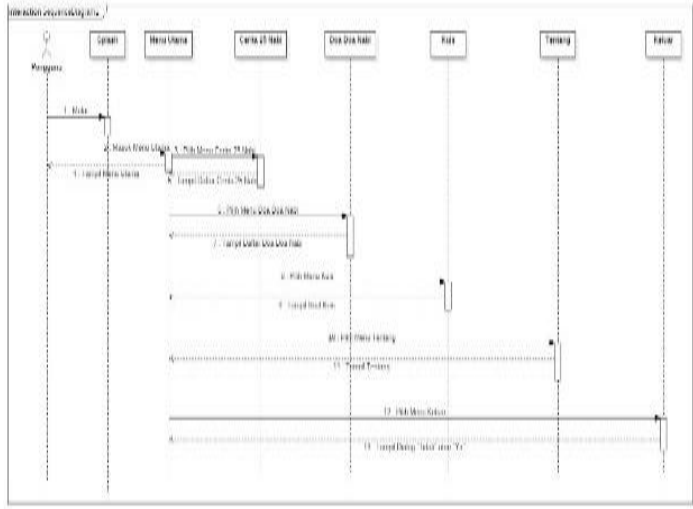

Gambar 6. Sequence Diagram Menu Utama

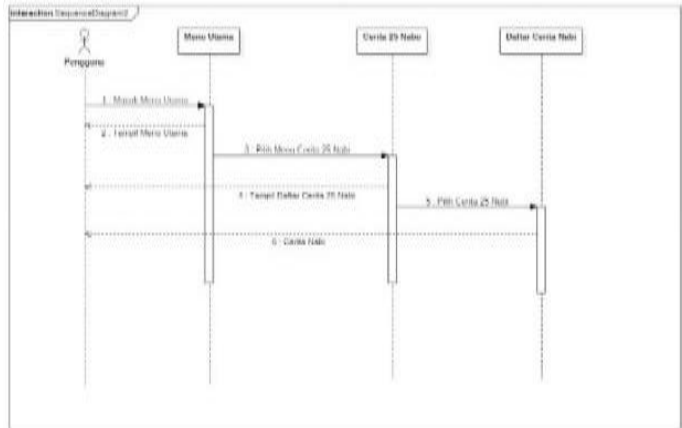

Gambar 7. Sequence Diagram Cerita 25 Nabi

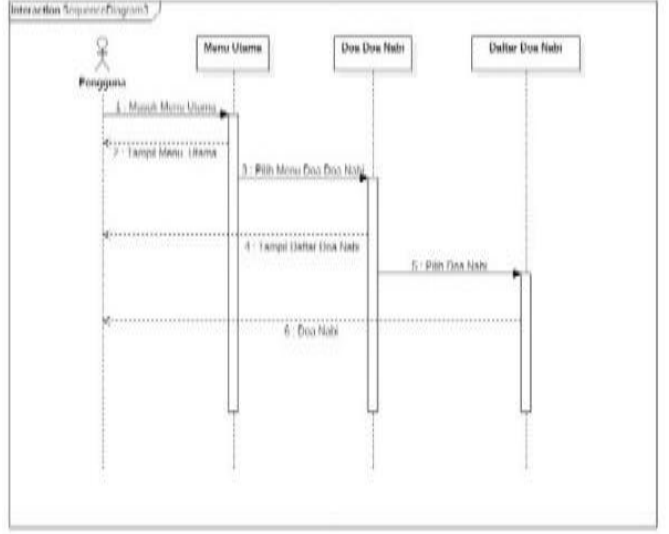

Gambar 8. Sequence Diagram Doa Nabi

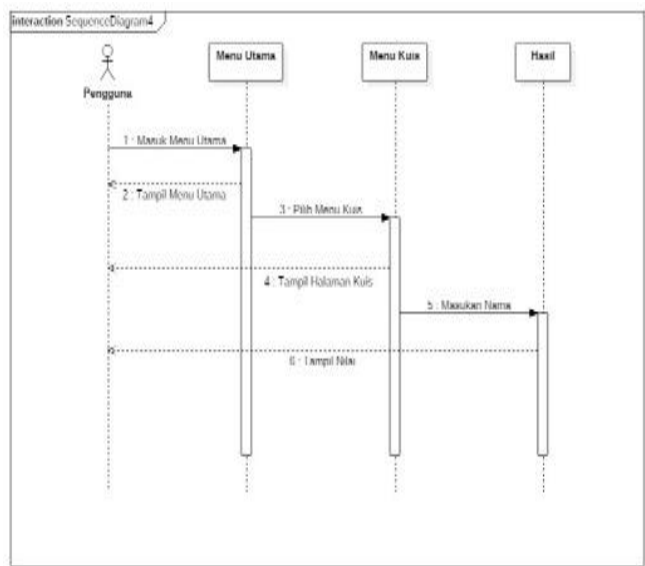

Gambar 9. Sequence Diagram Kuis 


\section{Tampilan Aplikasi Cerita Nabi dan Doa Nabi}

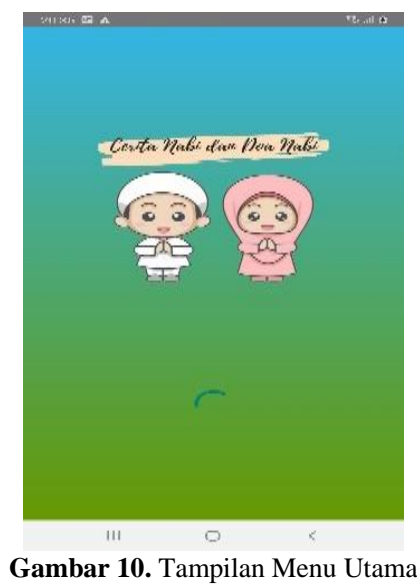

Pada gambar 10 saat pengguna memulai aplikasi maka akan menampilan splashscreen terlebih dahulu sebelum masuk ke menu utama.

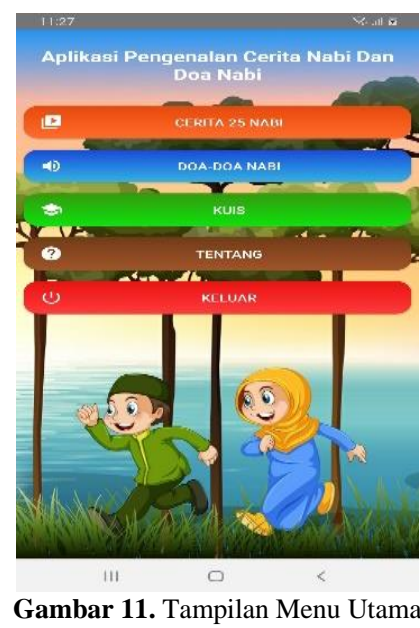

Pada gambar 11 menampilkan tampilan menu utama pada aplikasi cerita Nabi dan doa Nabi. Terdapat pilihan menu lainnya seperti cerita $25 \mathrm{Nabi}$, doa-doa Nabi, kuis dan tentang.

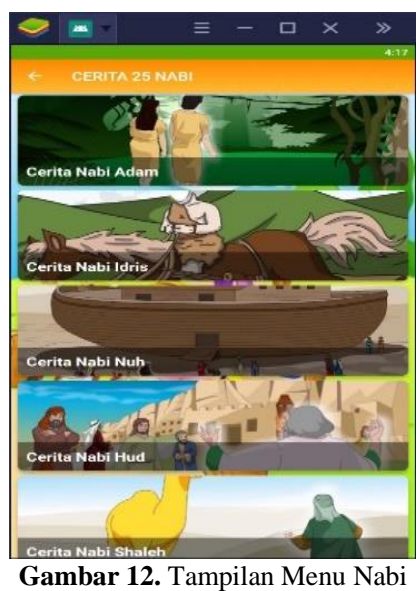

Pada saat pengguna memilih menu cerita 25 Nabi, maka akan menampilkan list 25 Nabi seperti pada gambar 12 . 


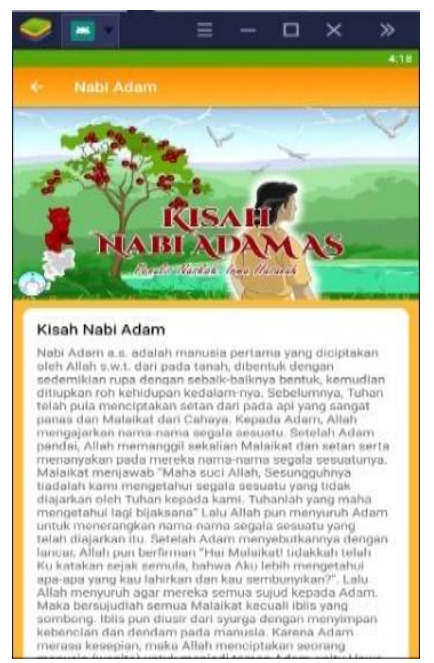

Gambar 13. Tampilan Cerita Nabi

Setelah pengguna memilih cerita Nabi Adam maka akan seperti gambar 13, di dalamnya terdapat video animasi dan teks cerita.

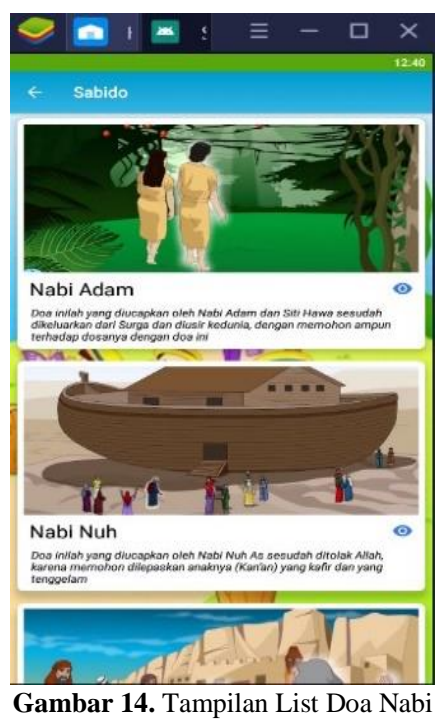

Pada saat pengguna memilih menu doa Nabi maka akan menampilkan list doa Nabi seperti pada gambar 14.

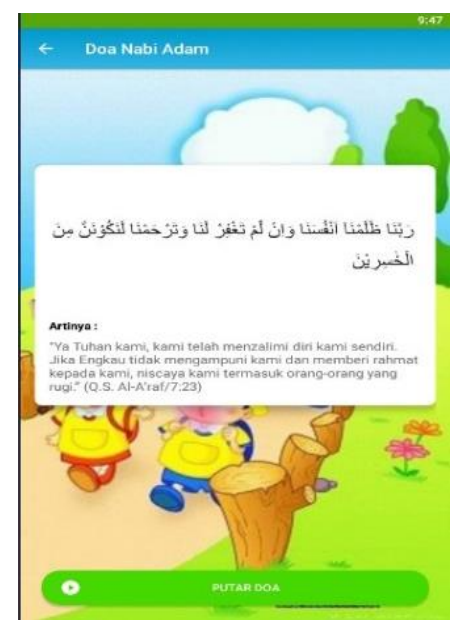

Gambar 15. Tampilan Doa Nabi 
Setelah pengguna memilih doa Nabi Adam maka akan seperti gambar 15, di dalamnya terdapat audio doa beserta artinya.

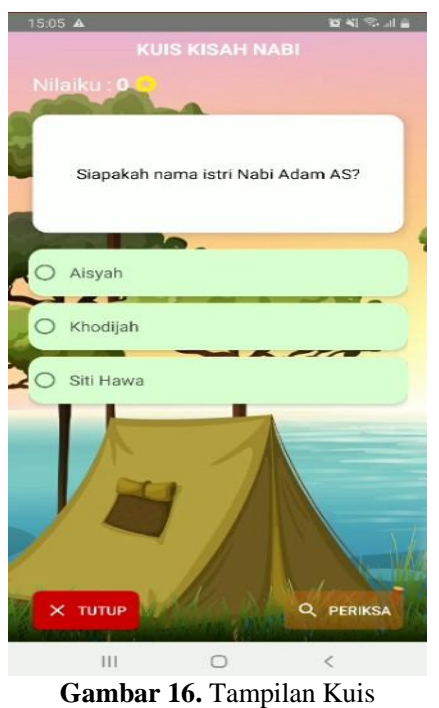

Pada saat pengguna memilih menu kuis maka akan menampilkan soal kuis seperti pada gambar 16.

\section{SIMPULAN}

Dengan dibuatnya aplikasi cerita Nabi dan doa Nabi berbasis Android ini maka dapat disimpulkan Pertama pada aplikasi ini mempelajari sejarah Nabi beserta doa-doa yang diamalkan oleh Nabi, oleh karena itu terutama untuk anak-anak supaya bisa mengetahui sejak dini. Kedua Aplikasi ini mengandung unsur edukasi, yang dimana aplikasi ini menyediakan fitur kuis.

\section{DAFTAR PUSTAKA}

A. S., Rosa dan Shalahuddin, M. 2013. "Rekayasa Perangkat Lunak Terstruktur Dan Berorientasi Objek." Bandung: Informatika.

Afriansyah, Aidil. 2018. “APLIKASI TUNTUNAN DO'A-DO'A HARIAN UMAT MUSLIM BERBASIS ANDROID.” Jurnal Teknologi Informasi Dan Komputer.

Gun Gunawan, Gun, and H. Bunyamin. 2016. "Pengembangan Aplikasi Kisah 25 Nabi Dan Rasul Berbasis Android." Jurnal Algoritma 12(2):298-295. doi: 10.33364/algoritma/v.12-2.298.

Hidayat, Wahyu. 2016. "Perancangan Media Video Desain Interior Sebagai Salah Satu Penunjang Promosi Dan Informasi Di Pt . Wans Desain Group.” Perancangan Media Video Desain Interior Sebagai Salah Satu Penunjang Promosi Dan Informasi Di Pt. Wans Desain Group.

Indrajit, Richardus Eko. 2011. "Peranan Teknologi Informasi Dan Internet." Yogyakarta: Andi Offest.

Kusmanto. 2018. "Perancangan Aplikasi Pendataan Suplayer Getah Karet Pada Pt. Rubber Hock Lie Menggunakan Visual Basic.Net.” Jurnal INFOTEK.

Nazruddin Safaat H. 2012. Android : Pemrograman Aplikasi Mobile Smartphone Dan Tablet PC Berbasis Android (Edisi Revisi).

Pressman, Roger S., Bruce R. Maxim. 2014. Software Engineering A Practitioner's Approach.

Rizky, Soetam. 2011. Konsep Dasar Rekayasa Perangkat Lunak. Jakarta: Indonesia.

Sugiyono, Prof. Dr. 2013. Metode Penelitian Kuantitatif, Kualitatif,Dan R\&D. 